recurrent falls. $19 \%$ were living sedentarily, $11 \%$ currently smoking, $10 \%$ drinking 3 or more units of alcohol-per-day and $31 \%$ having poor dietary calcium, with $22 \%$ having 2 or more of these lifestyle OPRFs. Of the medicines, steroids and PPIs were the most commonly seen. Overall, $73 \%(147 / 201)$ of subjects had at least one modifiable OPRF with over half having 2 or more OPRFs.

Conclusion: This study identified numerous OPRFs and their incidences. Low $\mathrm{BMI}(<18.5)$ was common in $1 / 5$ patients requiring input from the dietetics team as part of their treatment plan. Early menopause was seen in a quarter of female patients with just over $10 \%$ of these being offered HRT; undoubtedly more could have benefited from intervention at menapause. Many medical conditions associated with OP were identified with several patients being newly diagnosed (coeliac/hypothyroidism/haematological disorders especially). Therefore, global health assessments are needed to identify undetected disease and review and optimise control of established disease. Just under $50 \%$ had at least one lifestyle OPRF. Therefore, focus on implementing lifestyle alterations is clearly essential in the management of these patients. Given the high number of patients with at least one modifiable OPRF, it is crucial that OP services are organized accordingly to identify OPRFs to intervene and modify these factors as part of the overarching management plan.

Disclosure of Interests: None declared

DOI: 10.1136/annrheumdis-2019-eular.652

\section{AB0848 BMD AND MUSCLE MASS IN PATIENTS WITH ISCHEMIC HEART DISEASE}

Tatiana Raskina ${ }^{1}$, Inessa Grigoreva ${ }^{1}$, Olga Barbarash ${ }^{2}$, Alexander Kokov², Vladislava Masenko ${ }^{2} .{ }^{1}$ Federal State Educational Institution of Higher Education "Kemerovo State Medical University", Kemerovo, Russian Federation; ${ }^{2}$ Federal State Budgetary Scientific Institution "Scientific-Research Institute of Complex Issues of Cardiovascular Disease", Kemerovo, Russian Federation

Background: Mounting biological and epidemiological evidence supports a link between the ischemic heart disease (IHD) and osteoporosis (OP), but the studies investigating muscle mass and its relationship with $\mathrm{OP}$ in patients with IHD are limited.

Objectives: The aim of this study is to investigate the relationship between OP and muscle mass in patients with IHD.

Methods: The study included 45 patients with IHD (36 males/9 females, mean age $63,16 \pm 6,71$ years) verified by coronary angiography. BMD was measured by DXA in the the lumbar spine L1-L4, total hip and femoral neck. BMD was evaluated as: normal BMD (T-score $\geq-1$ ), osteopenia (Tscore between -1 and -2.5 ) and osteoporosis (T-score of $<-2.5$ ). Muscle mass was assessed using computed tomography of total psoas area (TPA) (cm2) and calculating L3 muscle index (LMI) $(<52,4 \mathrm{~cm} 2 / \mathrm{m} 2$ in men; $<38,5 \mathrm{~cm} 2 / \mathrm{m} 2$ in women).

Results: The results of densitometry patients were distributed as follows: 30 patients $(66,6 \%)$ with normal BMD, $12(26,6 \%)$ with osteopenia and 3 $(0.66 \%)$ with osteoporosis. Patients was divided into 2 groups: 1) nonosteopenia-nonOP and 2) osteopenia/OP. Mean femoral neck BMD was $1,024 \pm 0,09 \mathrm{~g} / \mathrm{cm} 2$ and $0,809 \pm 0,06 \mathrm{~g} / \mathrm{cm} 2$, respectively. L1-L4 BMD was $1,260 \pm 0,14 \mathrm{~g} / \mathrm{cm} 2$ for normal BMD group and 1,154 $\pm 0,16$ for osteopenic/ OP group. Patients with osteopenia/OP had statistically significant lower LMI $(45,57 \pm 4,66 \mathrm{~cm} 2 / \mathrm{m} 2$ vs. $52,78 \pm 10,24 \mathrm{~cm} 2 / \mathrm{m} 2, p=0,01$ for low femoral neck BMD; $46,33 \pm 6,97 \mathrm{~cm} 2 / \mathrm{m} 2$ vs. $52,76 \pm 6,74 \mathrm{~cm} 2 / \mathrm{m} 2, p=0,02$ for low L1-L4 BMD, respectively). According to the correlation analysis a positive relationship between L1-L4 BMD and LMI was revealed $(r=0,373, p<0,05)$. There was no correlation between femoral neck BMD and LMI $(r=0,272$, $\mathrm{p}=0,274$ )

Conclusion: The decline in BMD in IHD patients is associated with low muscle mass and correlated with severity of BMD dissension in the lumbar spine, but not in the neck of the femur. The obtained results confirm high probability of existence of common pathogenetic links between OP and sarcopenia.

Disclosure of Interests: None declared

DOI: 10.1136/annrheumdis-2019-eular.3662

\section{AB0849 CAUSES OF EARLY MORTALITY IN PATIENTS WITH OSTEOPOROTIC HIP FRACTURES}

Tatiana Raskina, Julia Averkieva, Tatiana Protasova, Inessa Grigoreva. Federal State Educational Institution of Higher Education "Kemerovo State Medical University", Kemerovo, Russian Federation

Background: Osteoporosis (OP) is a skeletal disorder characterized by compromised bone strength, which predisposes the individual to an increased risk of fractures of the hip, spine, and other skeletal sites. OP, a major public health problem, is becoming increasingly prevalent with the world population and occupies a leading place in the structure of morbidity and mortality.

Objectives: To study the causes of mortality in patients with hip osteo porotic fractures during 6 months after injury.

Methods: 432 patients with osteoporotic hip fractures were under observation. During the study, mortality rates were assessed both in hospital and during the first 6 months after the fracture. The main causes of mortality were tracked by ICD-10 classes. Information about fractures and their outcomes was obtained from data from the archives of the trauma departments of Kemerovo, city registry offices, telephone interviews of patients and their relatives.

Results: In the first 6 months after injury, 95 out of 432 patients died Overall mortality was $22.0 \%$. In the group of deceased patients, females prevailed: 73 women (16.5\%) and 22 men $(5.1 \%) \quad\left(\chi^{2}=4.4 ; p<0.0001\right)$ It was established that 6 months after a hip fracture in $63(66.3 \%)$ patients, death occurred from cardiovascular system diseases: in men $13(59.0 \%)$ cases and in women - 50 (68.4\%) ( $p=0.9)$. Respiratory diseases, as the cause of death, were detected in $18(18.9 \%)$ patients (in men - $5(22.9 \%)$ cases and in women - $13(17.8 \%)(p=0.1))$, oncological diseases - in $10(10.5 \%)$ men and women: $2(9.1 \%)$ and $8(10.9 \%)$ cases, respectively $(p=0.5)$. Diseases of the digestive system accounted for a small percentage of the total number of deaths $(3.2 \%)$, without statistically significant differences by gender (1 (4.5\%) case for men and 2 $(2.9 \%)$ cases for women $(p=0.75))$. Among the dead men, $1(1.1 \%)$ death was caused by an infectious disease.

Conclusion: During all periods of observation, most of the deceased men and women had cardiovascular and respiratory diseases.

\section{REFERENCE}

Disclosure of Interests: None declared

DOI: 10.1136/annrheumdis-2019-eular.5786

\section{AB0850 THE LIPID SPECTRUM OF BLOOD, DEPENDING OF BONE MINERAL DENSITY (BMD) IN MEN WITH CORONARY HEART DISEASE (CHD)}

Tatiana Raskina ${ }^{1}$, Anna Voronkina ${ }^{2}$, Marina Letaeva ${ }^{1}$, Olga Barbarash ${ }^{3}$, Vyacheslav Fanaskov ${ }^{4} .{ }^{1}$ Federal State Educational Institution of Higher Education "Kemerovo State Medical University", Kemerovo, Russian Federation; ${ }^{2}$ State Autonomous Healthcare Institution of the Kemerovo region "Regional Clinical Hospital of Emergency Medical Care named M. Podgorbunsky", Kemerovo, Russian Federation; ${ }^{3}$ Federal State Budgetary Scientific Institution "ScientificResearch Institute of Complex Issues of Cardiovascular Disease", Kemerovo, Russian Federation; ${ }^{4}$ State Autonomous Healthcare Institution of the Kemerovo Region "Regional Clinical Hospital for War Veterans", Kemerovo, Russian Federation

Background The problem of the relationship between osteoporosis in men and risk factors for atherosclerosis is insufficiently studied.

Objectives The aim was to assess the lipid profile of the blood depending on the BMD in men with CHD.

Methods 93 men older than 50 years (mean age $-60.8 \pm 6.9$ years) with coronary artery disease verified by coronary angiography were examined. The concentration of total cholesterol (OHS), triglycerides (TG), high and low density lipoprotein cholesterol (HDL and LDL cholesterol) in serum was determined by spectrophotometric method. T-criterion of the femoral neck and lumbar spine was used for the assessment of BMD, which was investigated by the method of two-energy absorptiometry (densitometer Excel XR-46, NORLAND, USA). According to the T-criterion, patients were divided into 3 groups: I - 30 patients with osteoporosis (T criterion $\leq-2.5$ ), II -44 patients with osteopenia (T-criterion from -1 to -2.5 ) and III -19 men with normal BMD (T-criterion $\geq-1)$.

Results Most men with established CHD dyslipidemia (95.7\% of patients): hypercholesterolemia $-76.3 \%$, elevated level of LDL cholesterol $-81.7 \%$ of the patients, hypertriglyceridemia in $49.5 \%$, a decrease in the concentration of HDL cholesterol $-44.1 \%$ of cases. In all three groups of patients hypercholesterolemia $(80,75$ and $73.7 \%$ of patients in groups I, II and III, p>0.05) and increased LDL-C concentration $(83.3,84.1$ and $73.7 \%$ of men in groups I, II and III, p>0.05) were revealed. Reduction of HDL cholesterol level was determined in $46.7 \%$ of cases in group I, 43.2\% in group II and $42.1 \%$ in group III ( $p>0.05)$. Hypertriglyceridemia was registered in $60 \%$ of patients with osteoporosis, $43.2 \%$ - with osteopenia and $47.4 \%$ - with normal BMD ( $p>0.05)$. Correlation analysis of the relationship of lipid metabolism with the T-criterion in all patients included in the study did not revea significant relationships ( $\mathrm{p}>0.05)$.

Conclusion The results of the study indicate the presence of severe dyslipidemia and the absence of dependence of lipid parameters on the state of BMD in men with $\mathrm{CHD}$. 